\title{
Negotiating Performance
}

\section{Diana Taylor}

Para esta conferencia dedicada al teatro latinoamericano, George Woodyard me asignó la tarea de hablar acerca de "Performance." Esto me interesó muchísimo; de hecho Juan Villegas y yo estamos editando un libro sobre el asunto titulado Negotiating Performance. Pero ya de entrada el tema me presento dos problemas interesantes. Para empezar, la palabra "performance" en inglés tiene varios sentidos contradictorios. Más problemático aún es que no existe la palabra equivalente a "performance" en español. El concepto térico que a mí me interesa discutir aquí aún no se ha analizado sistemáticamente en nuestro campo y nos falta un vocabulario adecuado para hacerlo. Pues bien, me dije, daré la ponencia en inglés y ya está. (Fue durante esta etapa que propuse el título en inglés que ven en el programa.) Pero después de reflexionar un poco más, se me hizo importante iniciar aquí un díalogo acerca de los múltiples sentidos de la palabra "performance" ya que, aunque nos falte el vocabulario, el fenómeno mismo tiene una larga y rica tradición en nuestras culturas que, simplemente, no se ha teorizado. Quisiera explorar las nuevas posibilidades teóricas que nos ofrece el concepto en nuestras labores como teatristas y como latinos/as o latinoamericanistas y dar un par de ejemplos de Negotiating Performance del tipo de investigación que nos permite realizar.

En inglés, "performance" se ha utilizado generalmente para referirse a dos fenómenos que son esencialmente antitéticos. En su sentido más común, la palabra se podría traducir como puesta escénica o mise en scene. Si el teatro se considera un arte híbrido-texto y espectáculo-performance se definiría en oposición al texto dramático, un sub-género teatral. En su otro sentido, performance ha llegado a significar casi lo opuesto de teatro; se ha independizado para constituirse en diversas formas anti-teatrales que resisten categorización: performance art, public art, instalaciones vivas, etcétera. En teoría, performance art rechaza la institucionalización del teatro e intenta subvertir un sistema de representaciones acusado de ser cómplice de un sistema social represivo. En esta ponencia, me interesa explorar no sólo este segundo fenómeno sino también un tercer sentido de performance que abarca, pero va más allá de 
los dos que acabo de señalar. Más que un producto dramático-sea una puesta tradicional o de performance art-performance significaría el proceso mismo de teatralización social, el acto de asumir o re-presentar o atacar un rol proviniente de nuestros limitados repertorios sociales para fines que van más allá de lo estético. Por ejemplo, en vez de la noción dramática tradicional de la representación de un rol "femenino," podríamos proponer, como lo hacen las feministas desde Simone de Beauvoir a Judith Butler, que lo "femenino" es ya en sí una representación social con graves consecuencias concretas. Lo "femenino," como género sexual, entonces, no podría considerarse como una categoría estable o natural sino un performance, la teatralización de normas patriarcales. La teatralización social no es antitética ni al teatro ni al performance art sino que sería el elemento deconstructivo capaz de cuestionar la ideología subyacente de todo sistema cultural de representación. Este tercer aspecto de performance, desafortunadamente, suele excluirse de nuestras discusiones.

Indudablemente, el estudio de performance en su primer sentido de texto escenificado ha sido, y sigue siendo, de gran interés para todos nosotros-académicos, dramaturgos, directores, actores, y los demás artistas técnicos involucrados en un montaje. Sin embargo, las limitaciones conceptuales de esta definición son obvias-especialmente para los latinos, los latinoamericanistas, pueblos colonizados que tienen poblaciones mixtas en términos raciales y lingüísticos. Si nos limitamos a pensar en performance como texto escenificado nos vamos a encontrar con varios problemas:

1) La noción clásica del teatro (en su sentido más amplio de actividad mimética que se desarrolla en un espacio no-cotidiano para un público exclusivo) va a reducir el tipo de actividad que se podría calificar como "teatro." $\mathrm{Si}$ consideramos sólo textos escenificados entramos en toda una red económica que excluye la gran mayoría de nuestras poblaciones. ¿Quién tiene aceso a producir o consumir las funciones/ediciones? Fuerzas económicas determinan en muchos casos las obras que se van a publicar o montar. Sin embargo, si pensamos en performance, podemos discutir espectáculos que no se limitan a esa red económica-espectáculos callejeros, carnaval, festivales y manifestaciones públicas, etcétera.

2) Nos encontramos con un canon que refleja, a nivel superficial, modas y modelos dominantes. Dada la historia de colonización que compartimos, este hecho es comprensible. La producción y recepción de nuestras obras son mediadas por los grandes centros culturales europeos o norteamericanos. Es una vieja historia que seguramente todos conocemos pero nos crea problemas específicos con los cuales tenemos que bregar tanto los dramaturgos como los críticos. Nuestros dramaturgos y públicos, en su mayoría, tienen poco contacto directo entre sí-en México, no se conocen las obras argentinas o chicanas. En 
Guatemala no se pueden comprar ni las mismas obras guatemaltecas. Pero siempre se encuentran las obras de Ibsen o Shakespeare o S6focles. Nuestros productos teatrales, marginales y minoritarios en relación a la metrópolis, son considerados "menores" y "poco originales" en comparación con las obras maestras dominantes que son elogiadas por su originalidad y valor universal. Aunque estos prejuicios nos parezcan transparentes, nos restringen. Yo, como investigadora, me veo forzada a combatirlos y rectificarlos. Quiera o no, me encuentro atrapada por un sistema de valores eurocéntricos que eclipsa los fenómenos que a mí me interesan. Mientras que críticos del llamado "primer mundo" se dedican a analizar "tropes of visibility," nosotros, desde los márgenes oscurecidos, estamos intentando salir de la invisibilidad. Sólo después de introducir los contextos socio-políticos, históricos y culturales podemos entrar en la discusión sobre nuestros teatros. Pero si dejamos de pensar en términos de teatro, tal vez podamos establecer otra red de diálogo e interacción. En lugar de hablar del teatro de Griselda Gambaro (para dar un ejemplo) a nivel de tradiciones e influencias dramáticas, podríamos situar su obra en relación al holocausto, o la teatralización política de las Madres de la Plaza de Mayo o la escritura de mujeres-niveles en que no se podría considerar "menor" en relación a modelos "universales."

3) Nuestro canon dramático excluye (con pocas excepciones) a escritoras femininas o a dramaturgos de razas menospreciadas (no se puede decir que sean minoritarias). Lo lógico sería concluir (como se ha hecho por cierto) que las mujeres no hacen teatro, o que los indígenas, por ejemplo, o los afro-caribeños, son "primitivos." Para los que asiertan que "el teatro es la flor de la civilización" los que no tienen teatro no tienen cultura. Y no hace falta remontar a la epoca de la conquista para saber qué destino le espera aún hoy a la gente "sin cultura." Claro está que para poder apreciar cómo las mujeres latinoamericanas o latinas han buscado espacios (considerados históricamente como no-teatrales) para apoderarse de los medios de auto-expresión y representación en sociedades patriarcales, o cómo diversos grupos étnicos marginados han utilizado técnicas dramáticas (muchas veces de orígenes pre-hispánicas) para fines religiosos o políticos, tenemos que re-analizar tanto el concepto eurocéntrico de la "Cultura" como el del teatro como su máxima expresión. Al hacerlo, nos encontramos con múltiples expresiones dramáticas de una fuerza e importancia indiscutible-desde el performance art de Jesusa Rodríguez en México a las manifestaciones de las Madres de la Plaza, desde las fiestas/bailes populares de grupos afro-caribeños al uso político del espectáculo por parte de los indígenas del Ecuador y los quehaceres religiosos en la iglesia por mujeres que no tienen otra forma de expresión pública. 
Estas limitaciones que acabo de señalar se pueden evitar si ampliamos nuestras nociones acerca de lo teatral para facilitar nuevas direcciones. Antes de entrar en esto quisiera enfatizar que no todo el teatro (textos/puestas) refleja o apoya este sistema coercivo-he dedicado estudios al tema y no creo que haga falta reiterar mis argumentos aquí. La pregunta tal vez sería la siguiente: si el teatro-que es un sistema de representaciones entre varios-hace más que re-crear la ideología dominante ¿cómo es que logra criticar o subvertirla? El teatro, que no por nada tiene el mismo nombre que el edificio que lo alberga, es una institución social. A partir de los años ' 60 , más y más dramaturgos y estudiosos latinoamericanos/latinos han reconocido que el teatro en nuestras sociedades ha funcionado como un sistema de exclusiones y represiones y que, históricamente, ha servido intereses colonizadores, elitistas y patriarcales. Para compensar, se ha intentado ampliar el canon introduciendo categorías teatrales dedicadas a recuperar o incluir lo que tiende a excluirse. Vemos, por ejemplo, referencias a "teatro de mujeres" o a "teatro indígena" (entre muchos otros). También se ha intentado incluir a estos marginados en las obras, las puestas, y en los estudios académicos dedicados a ampliar el canon. Este proyecto es admirable pero yo lo encuentro insuficiente. No cabe duda que es importante reunir y editar trabajos escritos por grupos minoritarios y darles mayor visibilidad. Pero el problema no es sólo uno de intención. Hace falta analizar cómo la mécanica de la representación en el teatro tiende a re-crear los problemas que, en teoría, intentamos evitar. Después de examinar brevemente dicha mécanica, quisiera sugerir como el concepto de performance nos ofrece una salida.

El teatro, según Patrice Pavis, como las otras artes de representación, tiene "un doble nivel: lo representante (la obra) y lo representado (la realidad figurada)." Pero, añade Pavis,"el teatro es el único arte figurativo que se 'presenta' al espectador sólo una vez" (422). Si regresamos a mi ejemplo de la representación de la mujer, podemos identificar el problema que nos crea esta formulación teatral. No es solamente que la mayoría de las obras latinas o latinoamericanas suelen representar a pocas mujeres. Ni tampoco que las que salen tienden a desempeñar papeles tradicionales. Inclusive las obras-escritas por hombres o mujeres-que se enfocan en la mujer raras veces cuestionan la figuración de "mujer" en una sociedad patriarcal que la constituye como el otro, es decir, en oposición al sujeto masculino. ¿A quién realmente pertenece la voz, el deseo, la fantasía dizque "femenina?" En parte, el ventriloquismo masculino teatral podría atribuirse a la falta de conscientización a nivel personal y colectivo. En parte, es un problema inherente a la representación teatral.

Si re-examinamos lo que nos dice Pavis acerca del doble nivel de teatro como representante y representado llegamos al grano. Según esta dicotomía, la 
mujer en una obra dramática ocuparía este segundo nivel—lo representado, objeto (no sujeto) de representación. Esto la condena a una posición fija y estable ("la realidad figurada") aun cuando, teoricamente, el proyecto es ganarle mayor visibilidad y autonomía. Pero, como nos han señalado las críticas femenistas, la mujer no existe fuera de la representación-no es objeto sino producto de la representación. Como dijo Simone de Beauvoir, "una no nace, sino que se convierte en mujer." Y, como comenta Judith Butler sobre la observación de Beauvoir,

[w]hen Beauvoir claims that 'woman' is a historical idea and not a natural fact, she clearly underscores the distinction between sex, as biological facticity, and gender, as the cultural interpretation or signification of that facticity. To be female is, according to that distinction, a facticity which has no meaning, but to be a woman is to have become a woman, to compel the body to conform to an historical idea of 'woman,' to induce the body to become a cultural sign, to materialize oneself in obedience to an historically delimited possibility, and to do this as a sustained and repeated cultural project ("Performative Acts", 273).

En el paradigma de Pavis, la mujer sería representante y representado-simultáneamente la teatralización o actualización de un rol ("becoming") y su figuración. Pero este doble proceso es difícil de captar en el teatro porque, al introducir a la mujer físicamente en la escena, el cuerpo femenino ("biological facticity") ya se ha convertido en un "cultural sign," es decir, ya ha asumido el papel de "natural fact," de objeto "representado" que, teoricamente, se intenta criticar.

Este problema-inherente a todo arte de representación, es más agudo en el teatro ya que introduce cuerpos vivos a la escena. ¿Es concebible siquiera, un teatro que pueda subvertir esta situación paradojica? ¿Será posible desmantelar un sistema de representación patriarcal que enfatiza un rígido sistema binario basado sobre la diferenciación primaria: masculino/femenino? ¿La mujer sólo puede defenderse, como nos demuestra Sabina Berman en El suplicio del placer, apoderándose del rol (en este caso el bigote) masculino? Los roles sexuales siguen intactos aunque sean intercambiables. Performance art hecho por mujeres nace como estrategia para desajustar el sistema teatral tradicional y hacer visible la ideología patriarcal subyacente. Una artista feminista, por ejemplo, tiene un número de Strip Tease en el cual cada vez que se quita una prenda, en lugar de quedar desnuda, les entrega a los espectadores un fragmento minúsculo de una foto en la que ella está desnuda. Así, ella llama la atención a cómo la cosificación 
sexual de la mujer la reduce, metonímicamente, a "body parts"—senos, nalgas y caderas. La última cosa que les da a los espectadores es un pequeño espejo para que reconzcan su participación en este proceso deshumanizador y violento. ${ }^{2}$

¿Pero el teatro puede hacer lo mismo? Yo propongo que sí-utilizando las técnicas de performance. Diana Raznovich, en Casa matriz, problematiza lo que significa "mujer," específicamente madre e hija dentro de la sociedad argentina. En esta obra-el papel de Madre, por ejemplo, se reconoce como performance, como uno de los pocos roles femeninos bien recibidos en una sociedad patriarcal. La madre sustituta es, explícitamente, una actriz actuando un rol. Su identidad de "madre" no tiene nada que ver con la biología o con instintos "naturales." Ella es una profesional—sabe que será premiada por desempeñar bien su papel: "Soy la Mater sufriente por excelencia. Vestida de negro, limpiando, llorando . . . Soy la Gran Madre Sufriente. Soy la Madre Consagrada por el tango. La literatura se ha ocupado vastamente de mí. Soy una madre bíblica, 'parirás con dolor.' Soy la santa madrecita, ¡Mira qué lagrimones!" (179). El rol de madre en Casa matriz es, a la vez, representante y representado_el medio teatral ("becoming") y el contenido ("historically delimited possibility" = Madre). No hay realidad estable al nivel de contenido que se esté actualizando sobre la escena. Todo lo contrario - la realidad del rol materno es producto de teatralización; se repite a causa de su éxito social.

Performance, como una estrategia deconstructiva, nos permite de-estabilizar un sistema de representaciones basado en un sistema binario exclusivo y reificante. Esto se ve no sólo en términos masculino/femenino como señalé brevemente, pero también en toda una serie de oposiciones que, desmitificadas, facilitan una crítica a nivel de clase social, identidad étnica y sexual. Por razones de tiempo, me limito a dar dos ejemplos de Negotiating Performance: la oposición de espectáculo y espectador y la oposición entre la "cultura" y lo "primitivo."

En "Public Art, Performance Art and the Politics of Site," María Teresa Marrero discute la puesta escénica de Ignore the Dents, un "urban opera" del Chicano Daniel J. Martínez en el Million Dollar Theatre de Los Angeles en 1990. El teatro/cine, situado en una zona latina de clase obrera, no es frecuentado comúnmente por el público anglosajón de la clase media o alta de Los Angeles. Señala Marrero: "As the line of the 1,140 spectators . . . wound around several city blocks, they became the spectacle for the local residents, transients and corner drunks. This mix made an uneasy situation for some of those in line, as the street persons made no qualms about randomly speaking to those in line. After all, this is their 'territory.'" Los espectadores de repente pierden su posicion superior de "unseen see-er" y consumidores cuando se convierten en espectáculo. El foyer, nos explica Marrero, había sido transformado en un "art 
installation [which] funneled the spectators through monitored turnstiles, giving each spectator a small, cardboard cutout of a human head." Al entrar al teatro/cine, los espectadores vieron sobre la pantalla el video de las personas entrando en el foyer: "The voyeuristic thrill," Marrero nos dice, "was immediately tainted with the awareness that a few minutes before, my own image had been stolen from me and made available to another voyeuristic public.... By this time, the program informed us that we were in the Overture or third part of the opera. The Prelude has taken place on the street, the Antefatto while traversing the lobby" (20).

Aquí, pues, tenemos un ejemplo de performance en un sentido más amplio. No se limita a lo que pasa en el teatro-por más radical que sea. La puesta que describe Marrero contiene en sí la crítica de su propia escenificación. En Dents, los espectadores, miembros de la cultura dominante, dejan de estar en control; dejan de 'poseer la mirada.' Ellos son el "show." Como dice Marrero, "In a society that constantly attempts to walk past, not see, and ignore its downtrodden, this was a profoundly political and personal act. The kind of confrontation orchestrated by ... Dents provoked not only looking at the "other" but a profound inner look at ourselves" (18).

El segundo ejemplo tiene que ver con las "casitas" puertoriqueñas-que fueron originalmente habitadas por obreros en los años ' 40 y ' 50 en zonas rurales de la isla-y que se están construyendo actualmente en Nueva York. Las casitas en South Bronx son réplicas-con todo y el batey y el jardín, los patos y las gallinas-de las casitas puertoriqueñas, pero están situadas en lotes vacíos, a veces apretadas entre edificios altos. Algunas funcionan como centros culturales en las que la gente toca música, baila y come. Otras ofrecen servicios médicos, legales o lo que haga falta a la comunidad. Como señala Joseph Sciorra, "the casita is not only a nostalgic lament for an idealized past but a form of community organization whereby control of one's immediate environment is achieved through the use of traditional expressive culture" (158). ${ }^{3}$ Las casitas son una muestra concreta de performance al nivel cotidiano y popular. El concepto de las casitas como performance es iluminante porque subraya la idea que la cultura misma de todos los grupos diversos es arte-la gente se reconoce a sí misma y a los demás como parte de un sistema cultural vital que incluye la música, el baile, la cocina, la arquitectura y la pintura. Las casitas son simultáneamente representante y representado; son el vehículo expresivo y su figuración concreta. Como dice Juan Flores en Negotiating Performance: "Architectural shape and detail, extemporaneous and crafted decor, spatial arrangement and location conspire to lend the casita and its environs a unifying emblematic weight, and to convert the easy occasionality of the scene into an occasion of community history. Leisurely playfulness and everyday sociability, 
when in close range of the casita, become performance." Este ejemplo de lo que yo denominaría "performing culture" o "culture as performance" demuestra cómo cambia el significado de este "performance" cuando cambia de contexto. Flores examina lo que pasa cuando la casita es oficialmente reconocida como producto cultural y es trasladada al Smithsonian Institute en Washington bajo el título: "Las Casitas: An Urban Cultural Alternative": "The little building assumed an imposing but somewhat uncomfortable presence there in the center of that gaping, uncluttered space, and seemed intruded upon by the oohs and ahs of its sophisticated visitors as they filed up the 'cute' porch and into the 'quaint' interior. Lining the walls, the life-scale photos of 'real' casitas in their 'real' home setting helped bridge the gaps somewhat, as did the explanatory captions. ..." La casita, cultura en vivo en el barrio, se ha transformado en cosa-es decir, producto u objeto cultural. Este ejemplo me interesa no sólo porque sitúa la discusión de performance en un nivel cotidiano-tradicionalmente considerado no-cultural-pero porque nos hace reconsiderar lo que significa "cultura." En el momento que el Smithsonian simbólicamente "elevó" la casita al nivel de cultura la cuidad de Nueva York las estaba derrumbando por ser estructuras ilegales. Según las autoridades, no eran alternativas urbanas; eran un estorbo. Existe, pues una repudiación y valorización simultánea por parte de la cultura dominante. ¿Pero qué pasa cuando la "cultura" y el "arte" de una comunidad son atacados al nivel cotidiano y apropiados por las instituciones culturales? El separar el "arte" de lo "cotidiano"-como si fueran antitéticos-es enajenante para grupos minoritarios que no tienen acceso a lo que, tradicionalmente, se considera "arte." Pero el concepto de performance nos permite re-pensar nuestro quehacer dramático para evitar esta ruptura, para hacer un teatro que contenga la crítica de su propia escenificación, que ponga en tela de juicio las posibilidades y las limitaciones de su capacidad subversiva. $Y$ ya que George me ha pedido que hable acerca de performance, yo le voy a pedir a él que cambie el nombre de su revista a Latin American Theatre and Performance Review. ¿Cómo lo ven?

Dartmouth College

\section{Notas}

1. Hace dos meses los indígenas de Gran Chaco (los Matacos de Argentina) fueron víctimas del cólera. En vez de darles atención médica, el gobiemo de Salta impuso un estricto control militar para que otros-los civilizados-no contrajeran la enfermedad. Los Matacos intentaron huir, ya que en los años treinta los militares habían quemado las casas de las víctimas de una epidemia de viruela mientras que los enfermos estaban en ellas. ¿Por qué huyen ahora los Matacos? Un oficial comentó 
hace poco: "no tienen cultura ... ¿qué se puede esperar de ellos?" Information released by the "Foundation for the Promotion of Indian People 'Oyemboati'" and the South and Mesoamerican Indian Information Center. March, 1992.

2. Ver Barbara Freedman, "Frame-Up: Feminism, Psychoanalysis, Theatre" en Performing Feminisms: Feminist Critical Theory and Theatre, editado por Sue-Ellen Case. Baltimore: Johns Hopkins University Press, 1990.

3. The Drama Review, 34/4 (Winter) 1990: 156-168.

\section{Obras Citadas}

Berman, Sabina. "El suplicio del placer" en Teatro de Sabina Berman. México: Editores Mexicanos Unidos, 1985.

Butler, Judith. Gender Trouble: Feminism and the Subversion of Identity. New York: Routledge, 1990.

Case, Sue-Ellen, ed. Performing Feminisms: Feminist Critical Theory and Theatre. Baltimore: Johns Hopkins University Press, 1990.

Pavis, Patrice. Diccionario del teatro: Dramaturgia, estética, semiología. Barcelona: Ediciones Paidós, 1980.

Raznovich, Diana. "Casa Martiz" en Salirse de Madre, edición de Hilda Rais. Buenos Aires: Croquinel Ediciones, 1989.

Sciorra, Joseph. "'I Feel Like I'm in My Country': Puerto Rican Casitas in New York City." The Drama Review, Vol 34.4 (Winter, 1990): 156-168.

Taylor, Diana y Villegas, Juan (editores). Negotiating Performance in Latin/o America. (aún sin publicar). 